\title{
Stress-Optical Coefficient of Poly(ethylene oxide) and Poly(propylene oxide) Networks. Measurements
}

\author{
Toshihide IsHIKawa \\ Government Industrial Research Institute, Osaka, \\ Midorigaoka 1, Ikeda, Osaka, Japan. \\ (Received September 8, 1972) \\ KEY WORDS Poly(ethylene oxide) / Poly(propylene oxide) / Stress-
Optical Coefficient /
}

It has become known recently that the stressoptical coefficients of polymer networks which are swollen by optically and geometrically isotropic solvents are found to take minimum values. ${ }^{1}$ These results have been obtained for polyethylene, ${ }^{2,3}$ cis- and trans-1,4-polyisoprene, and cis- and trans-1,4-polybutadiene..$^{4-8}$ In this paper we attempt to treat experimentally poly (ethylene oxide), or PEO and poly(propylene oxide), or PPO which contain ether groups in the main chain.

A PEO raw material of viscosity-average molecular weight $M_{v} \simeq 10^{6}$ was obtained from the Seitetsu Chemical Company. The PEO sheets were crosslinked at room temperature by irradiating with $\gamma$-rays. The radiation doses were varied between about 30 and 50 Mrads. The PPO homopolymer and copolymer with allyl glycidyl ether $(3.3 \mathrm{~mol} \%)$ of $M_{v} \simeq 1.7 \times 10^{6}$, and $1.8 \times 10^{6}$, respectively, were supplied by the Tokuyama Soda Company. We preferred to use the crosslinked sheets of PPO copolymer because only a very weak crosslinking was achieved for the homopolymer. The PPO blocks were crosslinked by dicumyl peroxide (2 wt $\%$ ) and sulfur $(1 \mathrm{wt} \%)$ with a press temperature $150^{\circ} \mathrm{C}$ for $30 \mathrm{~min}$. The sample thickness was $1 \mathrm{~mm}$ through all measurements. We tried to estimate the linkage imperfections for PPO with the ozonized cleavage method explored by Price, et $a l .{ }^{9}$ The linkage irregularities were determined with a Hitachi K-53 gas chromatography using a 2-m column length packed with 20-\% PEG 6000 at $160^{\circ} \mathrm{C}$, and a helium flow of 50 $\mathrm{ml} / \mathrm{min}$. The results obtained are: head-to-tail units (I) $83 \%$, tail-to-tail units (II) $8 \%$, and head-to-head units (III) $9 \%$ for the homopolymer, while I is $80 \%$, and II and III are $10 \%$ for the copolymer. The results of the two types of samples are similar and in good agreement with that of Price, et al., ${ }^{9}$ for polymers from the $\mathrm{AlEt}_{3}-\mathrm{H}_{2} \mathrm{O}$ catalyst system. For the PPO sample with high linkage regularity or high crystallinity it was difficult to obtain a good crosslinking condition. Therefore, only limited stress-optical measurements were carried out for the various samples of PPO.

The stress-optical coefficient of Gaussian networks, $C$, is given by

$$
C=\frac{\Delta n}{\lambda V_{\mathrm{r}}^{2 / 3} f}=\frac{2 \pi}{45 k T} \frac{\left(\bar{n}^{2}+2\right)^{2}}{\bar{n}} \Delta \Gamma
$$

where $\Delta n$ is the birefringence, $\lambda$ is the elongation ratio, $V_{\mathrm{r}}$ is the volume fraction of polymer, $f$ is the stress referred to the unswollen, unstretched cross section, $\bar{n}$ is the mean refractive index of the sample, $k$ is Boltzmann's constant, $T$ is the absolute temperature, and $\Delta \Gamma$ is the stress-optical anisotropy of a Kuhn statistical segment. The measurements of swollen sheets were limited to only about a $10-15 \%$ elongation ratio as the sheets were quite weak.

The values of $\Delta \Gamma$ for PEO are given in Table I. The solvent choices are based on the theta solvent-temperature system found by Bailey and Callard $^{10}$ for aqueous salt solutions of No. 12 , and by Beech and Booth ${ }^{11}$ for methyl isobutyl ketone solution of No. 3. The choices are somewhat arbitrary for the others. The $\Delta \Gamma$ in the unswollen states are obtained from the 
Table I. Average values of $\Delta \Gamma$ for swollen and unswollen specimens of PEO

\begin{tabular}{llcccl}
\hline No. & Solvent & $V_{\mathrm{r}}$ & $\begin{array}{c}\text { Temp, } \\
{ }^{\circ} \mathrm{C}\end{array}$ & $\bar{n}$ & $\Delta \Gamma, \AA^{3}$ \\
\hline 1 & $0.45 \mathrm{M} \mathrm{K}_{2} \mathrm{SO}_{4}$ & 0.14 & 35 & 1.341 & 1.34 \\
2 & $0.39 \mathrm{M} \mathrm{MgSO}_{4}$ & 0.18 & 45 & 1.345 & 1.43 \\
3 & m.i.b.k. $^{\mathrm{a}}$ & 0.15 & 50 & 1.401 & 1.40 \\
4 & $\mathrm{CCl}_{4}$ & 0.13 & 40 & 1.454 & 1.35 \\
5 & Benzene $_{6}$ & 0.06 & 30 & 1.495 & 1.24 \\
6 & $p$-Xylene & 0.15 & 30 & 1.490 & 1.94 \\
7 & Dioxane & 0.08 & 30 & 1.421 & 1.38 \\
8 & $\mathrm{H}_{2} \mathrm{O}$ & 0.06 & 30 & 1.335 & 1.57 \\
9 & - & 1.00 & 70 & 1.458 & $1.31 \pm 0.18$ \\
\hline
\end{tabular}

a Methyl isobutyl ketone.

Table II. Average values of $\Delta \Gamma$ for swollen and unswollen specimens of PPO

\begin{tabular}{|c|c|c|c|c|c|c|}
\hline \multirow[t]{2}{*}{ No. } & \multirow[t]{2}{*}{ Solvent } & \multirow{2}{*}{$V_{\mathrm{r}}$} & \multirow{2}{*}{$\underset{{ }^{\circ} \mathrm{C}}{\mathrm{Temp}}$} & \multirow{2}{*}{$\bar{n}$} & \multicolumn{2}{|c|}{$\begin{array}{c}\Delta \Gamma, \AA^{3} \mathrm{a} \\
\lambda=1.15\end{array}$} \\
\hline & & & & & $\mathrm{a}$ & b \\
\hline 1 & Isooctane & 0.33 & 50 & 1.396 & 1.29 & - \\
\hline 2 & Cyclohexane & 0.21 & 25 & 1.421 & 0.82 & 0.87 \\
\hline 3 & Cyclohexane & 0.15 & 50 & 1.414 & 1.07 & - \\
\hline 4 & $\mathrm{CCl}_{4}$ & 0.12 & 25 & 1.458 & 1.10 & 1.20 \\
\hline 5 & Benzene & 0.10 & 25 & 1.494 & 1.30 & 1.46 \\
\hline 6 & $n$-Decane & 0.38 & 40 & 1.420 & 1.18 & - \\
\hline 7 & - & 1.00 & 70 & 1.442 & $1.93^{*}$ & 1.99* \\
\hline
\end{tabular}

a a, copolymer; b, homopolymer. The values of $V_{\mathrm{r}}$ and $\bar{n}$ are somewhat different from those of copolymer, but they are not shown here, $* \lambda=1.5$.

mean value of $\lambda=1.15-1.3$ at $70^{\circ} \mathrm{C}$ in the approximately rubbery state. It is noted from Table $\mathrm{I}$ that the $\Delta \Gamma$ of swollen and unswollen states of PEO are shown to take quite similar values $\left[c a .1 .35\left(\AA^{3}\right)\right]$ and are remarkably lower values than those obtained for polyethylene ${ }^{7}$ [ca. 4.0-9.5 $\left.\left(\AA^{3}\right)\right]$.

We next turn our attention to PPO. As can be seen in Figure 1, a peculiar behavior, deviation from the Brewster's Law, is observed for the copolymer, even in the swollen state with benzene and isooctane; i.e., the $\Delta \Gamma$ increases with increasing elongation ratio below $\lambda=1.5$. For homopolymer in the bulk state deviation from Brewster's Law could not be recognized within experimental error. Such phenomena can not be adequately explained by form effects or non-Gaussian effects of rubber networks. It

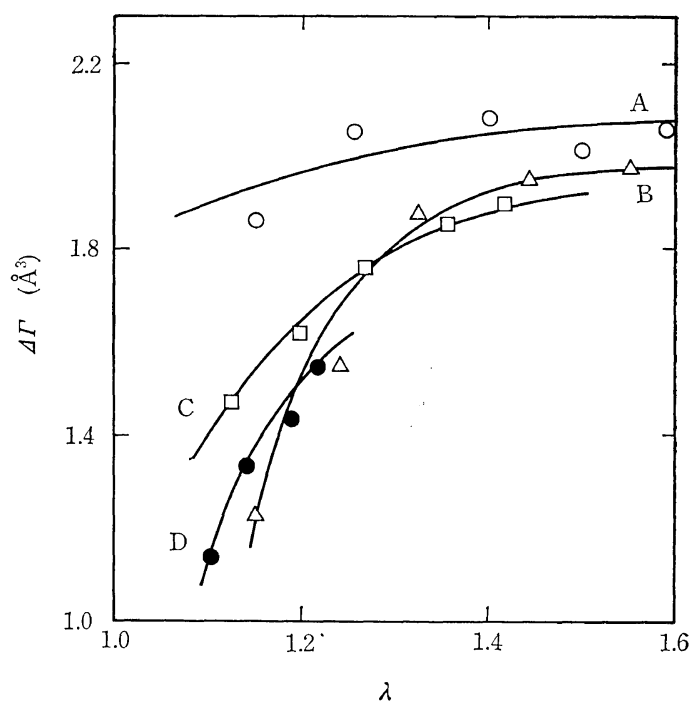

Figure 1. Optical anisotropy of PPO vs. elongation ratio. A, unswollen homopolymer; B, unswollen copolymer; C, swollen copolymer with isooctane; $\mathrm{D}$, swollen copolymer with benzene.

may be pointed out that the experimental error would mask the intrinsic value in the region of small birefringence and furthermore reorientation of the free branches of the allyl glycidyl ether groups in the copolymer would occur with increasing elongation. Considering this information, we have summarized the results for the two types of PPO in Table II. The values of $\Delta \Gamma$ for the swollen state are those at $\lambda=1.15$. Isooctane, No. 1 , is the theta solvent found by Allen, et al. ${ }^{12}$ The saturated values at $\lambda=1.5$ are chosen for unswollen samples, because these values are similar, and the orientation effect of the side groups may be eliminated. It is noted that the $\Delta \Gamma$ of PPO has a larger solvent effect than that of PEO. It is obvious that the intramolecular interaction is larger for the side groups of PPO than for PEO. We wanted to estimate the intrinsic value of $\Delta \Gamma$ for PPO, but the value obtained by the previous technique ${ }^{5,6}$ seems somewhat dubious. One possible reason is that the $\Delta \Gamma$ 's obtained with isotropic solvents are 0.87 in cyclohexane and $1.46\left(\AA^{3}\right)$ in benzene for the homopolymer at $25^{\circ} \mathrm{C}$. The discrepancy seems to go much beyond experimental error. Another aspect is disclosed by Hirano, et al. ${ }^{13}$ in that the sign of optical rotation for optically 
active PPO is inverted in the above solvents. It indicates the possibility of a conformational change in an isolated chain surrounded with isotropic solvent media, although there is a divergent opinion. ${ }^{14}$ The samples employed contain different linkages and stereoirregularities and these effects on the intrinsic value can not be estimated without the aid of theoretical calculations. In any event, the intrinsic value of $\Delta \Gamma$ seems to be obtainable from measurements in the bulk state for PEO, while care must be taken for PPO even in the swollen state in an isotropic solvent.

Acknowledgement. The author would like to thank Dr. K. Nagai for the encouragement during the course of this study and also Dr. M. Ukita of this institute for helping with the gas chromatography runs.

\section{REFERENCES}

1. K. Nagai, "Conformational Statistics of Polymeric Chains" in "Progress in Polymer Science Japan," Vol. 1, M. Imoto and S. Onogi, Eds.
Kodansha, Tokyo, 1971, P 215.

2. A. N. Gent and V. V. Vickroy Jr., J. Polym. Sci., Part A-2, 5, 47 (1967).

3. K. Nagai, J. Chem. Phys., 47, 4690 (1967).

4. A. N. Gent, Macromolecules, 2, 262 (1969).

5. T. Ishikawa and K. Nagai, J. Polym. Sci., Part $A-2,7,1123$ (1969).

6. T. Ishikawa and K. Nagai, Polymer J., 1, 116 (1970).

7. A. N. Gent and T.H. Kuan, J. Polym. Sci., Part A-2, 9, 927 (1971).

8. M. Fukuda, G. L. Wilkes, and R. S. Stein, ibid., Part A-2, 9, 1417 (1971).

9. C. C. Price, R. Spector, and A. L. Tumolo, ibid., Part A-1, 5, 407 (1967).

10. F. E. Bailey Jr., and R. W. Callard, J. Appl. Polym. Sci., 1, 56 (1959).

11. D. R. Beech, and C. Booth, J. Polym. Sci., Part A-2, 7, 575 (1969).

12. G. Allen, C. Booth, and C. Price, Polymer (London), 8, 397 (1967).

13. T. Hirano, P. H. Khanh, S. Akutsu, and T. Tsuruta, Preprint SPSJ 19th Symposium on Macromolecules, Japan, Kyoto, 1970 Part II, P 677.

14. T. Tsunetsugu, J. Furukawa, and T. Fueno, J. Polym. Sci., Part A-1, 9, 3529 (1971). 